\title{
MENADŽMENT U FUNKCIJI RASTA I RAZVOJA PREDUZEĆA
}

\author{
MANAGEMENT IN THE FUNCTION OF GROWTH AND \\ DEVELOPMENT OF ENTERPRISES
}

\author{
Vladimir Stojanović \\ Poslovni i pravni fakultet, „Union - Nikola Tesla" Univerzitet, Beograd, Srbija \\ Svetlana Ivanković \\ Srednja škola Barajevo, Barajevo, Srbija
}

CMESTE

JEL kategorija rada: M11, M21

\section{Apstrakt}

U savremenoj privredi uslovi za stvaranje konkurentske prednosti podložni su čestim promenama pa je zbog toga ona dinamična kategorija i zahteva kontinuiranu analizu i adekvatno reagovanje preduzeća u pronalaženju onih područja aktivnosti na kojima postoje značajnije šanse za postizanje poslovnog uspeha na tržištu, a uz izbegavanje poslova gde su prednosti na strani konkurencije. Ostvarivanje ciljeva i pravaca rasta preduzeća obuhvata značajne investicije u proširenje postojećih kapaciteta, ali i u izgradnju novih. Rast preduzeća podrazumeva jačanje osnovne delatnosti i/ili ulazak u nova područja poslovanja i samim tim i oštriju konkurenciju. Kreiranje održive konkurentske prednosti pretpostavlja sinergijsko delovanje vrednosnih i troškovnih pokretača, kao i izvora $i$ sposobnosti koje stvaraju pokretači. U isto vreme od menadžmenta preduzeća se očekuje da kreira takvu strategiju koja će sprečiti ili znatno umanjiti imitacije proizvoda ili proizvodnih procesa od strane konkurenata, kao i da obrazuje kupce kako se ne bi orijentisali ka supstitutima koje proizvode konkurenti. Značajan faktor kompetentnosti i uslov za ostvarenje konkurentne prednosti savremenog preduzeća jesu njegovi resursi, pa je ono konkurentno u meri u kojoj efektivno eksploatiše svoje resurse i onemogućava konkurente da imitiraju njegove strategije. Od strategijskog menadžmenta se očekuje da, raspolažući sa relevantnim signalima koji nose poruke iz okruženja, uvek uspostavlja takav odnos sa sredinom koji će mu omogućiti da ima prave ciljeve, da deluje u skladu sa mogućnostima i bude uvek u pripravnosti da deluje prema novim okolnostima i zahtevima okruženja. Najvažnije za rast, pa čak i za sam opstanak preduzeća je iznalaženje pozicije na tržištu koja je manje izložena opasnosti od napada direktnih protivnika, bilo da se radi o već afirmisanim ili novim preduzećima, odnosno manje ugrožena od strane direktnih kupaca, dobavljača i supstituta. Ovakva

Adresa autora zaduženog za korespodenciju: Vladimir Stojanović

㛃”maestros@gmail.com pozicija može da se uspostavlja na različite načine među kojima se mogu izdvojiti sledeći: učvršćivanjem odnosa sa najvažnijim klijentima, diferencijacijom proizvoda, uspostavljanjem 
tehnološkog liderstva u grani ili stupanjem u strategijske poslovne saveze kako bi se iskoristile sinergijske prednosti preduzeća na određenoj tržišnoj poziciji.

Ključne reči: strategijski menadžment, rast, preduzeće, konkurentnost, kompetentnost.

\section{Abstract}

In today's economy, conditions for creating competitive advantage are subject to frequent changes, which is why it is a dynamic category and requires continuous analysis and the adequate reaction of companies in finding those areas of activity where there are significant chances of achieving business success in the market while avoiding jobs where they are advantages on the competition side. Achieving the goals and directions of growth of the company includes significant investments in expanding existing capacities, but also in building new ones. The growth of a business involves strengthening its core business and/or entering new areas of business and therefore tougher competition. Creating a sustainable competitive advantage presupposes the synergistic action of value and cost drivers, as well as the resources and capabilities created by the drivers. At the same time, the management of the company is expected to create such a strategy that will prevent or significantly reduce imitation of products or production processes by competitors, as well as educate customers so as not to orient themselves to substitutes produced by competitors. A significant factor of competence and a condition for realizing the competitive advantage of a modern enterprise are its resources, so it is competitive to the extent that it effectively exploits its resources and prevents competitors from imitating its strategies. Strategic management is expected to always, with relevant signals carrying messages from the environment, establish such a relationship with the environment that will enable it to have the right goals, to act by its capabilities and to always be ready to respond to new circumstances and requirements surroundings. The most important thing for the growth and even the survival of the company is finding a position in the market that is less exposed to the threat of direct adversaries, be it already established or new companies, or less threatened by direct customers, suppliers, and substitutes. Such a position can be established in various ways, among which are the following: consolidating relationships with the most important customers, differentiating products, establishing technological leadership in the industry or joining strategic business alliances to take advantage of the synergistic advantages of a company in a particular market position.

Keywords: strategic management, growth, enterprise, competitiveness, competence.

\section{UVOD}

U savremenim uslovima poslovanja, preduzeća moraju svakodnevno da pronalaze nova rešenja kako bi održala i povećala svoju konkurentnost, koja je osnova za uspeh ili neuspeh svakog preduzeća (Porter, 2009).

Preduzeće stvara konkurentsku prednost tragajući za novim i boljim načinima za održanjem svoje konkurentske sposobnosti na postojećim tržištima i za osvajanjem novih tržišta. To implicira odgovarajuće inovativne aktivnosti u pogledu promena u proizvodima ili uslugama, promenama u poslovnim procesima, novih pristupa marketingu, novim oblicima distribucije, novim koncepcijama ekonomije raznovrsnosti. Najčešće inovacije koje vode stvaranju i održavanju konkurentske prednosti odnose se na upotrebu nove tehnologije, promene u zahtevima potrošača, potrebe za novim privrednim segmentima, smanjenje troškova inputa, promene u zakonskim regulativama i $\mathrm{dr}$.

Poslovni uspeh preduzeća ne leži samo u realizaciji njegove vizije, aspiracija i misije, nego predstavlja rezultat pažljive analize njegovih sposobnosti i kompetentnosti u savremenom okruženju. Naime, konkurentska prednost, zasnovana na distinktivnim sposobnostima koje preduzeće može u velikoj meri da kontroliše i razvija sve više postaje osnova njegovog poslovnog uspeha. Savremena preduzeća stvaraju vrednost uspešnim realizovanjem odnosno primenom svojih ključnih kompetentnosti u dinamičnom eksternom okruženju.

\section{POSLOVNI MENADŽMENT}

Menadžment je konstantan proces kojim se pokreće i usmerava poslovna aktivnost radi ostvarenja ciljeva poslovanja. Rezultat procesa usmeravanja je upravljačka odluka i njeno 
sprovođenje u poslovnoj aktivnosti. Od poslovnog menadžmenta se očekuje da, raspolažući relevantnim signalima koji nose poruke iz okruženja, uvek uspostavlja takav odnos sa sredinom koji će mu omogućiti da ima prave ciljeve, da deluje u skladu sa mogućnostima i bude uvek u pripravnosti da deluje prema novim okolnostima i zahtevima okruženja.

Za razliku od planiranja koje se kao periodična aktivnost preduzima da bi se preduzeće suočilo sa promenama u okruženju, poslovni menadžment uključuje kako odluke tako i poslovno ponašanje. (Đogić, 2007) Promene u sredini se posmatraju više kao mogućnost nego kao opasnost za preduzeće.

Proces poslovnog menadžmenta se može opisati kao tok istraživanja i kreiranja rešenja za ponašanje preduzeća kao i njihovo sankcionisanje relevantnim odlukama, uključujući i obezbeđivanje uslova za njihovu harmoničnu i pravovremenu implementaciju. Proces poslovnog menadžmenta uključuje nekoliko aktivnosti kojima se upravlja poslovanjem preduzeća. Te aktivnosti su (Đuričin \& Janošević, 2006):

1. Definisanje vizije i misije preduzeća, odnosno utvrđivanje osnovnih stavova za ostvarivanje uloge u datom sistemu privređivanja (misija).

2. Analiza i predviđanje promena u okruženju koja treba da na najbolji način postavi postojeće strategijske pozicije preduzeća.

3. Analiza i projekcija internih mogućnosti preduzeća, odnosno realistčko sagledavanje resursnih mogućnosti preduzeća kao uslova za njihovo aktiviranje ili pribavljanje.

4. Definisanje ciljeva, odnosno odgovarajuće opredeljivanje sa kojim poslovnim performansama ostvariti efektivno i efikasno poslovanje preduzeća.

5. Sagledavanje uslova i radnji koje preduzeće mora ispuniti da bi poslovalo $u$ određenom području delatnosti, u odnosu na koje će se tragati za izvorima za sticanje konkurentske prednosti.

6. Identifikovanje $i$ ocena strategijskih opcija $i$ izbor strategije, odnosno istraživanje mogućih pravaca, načina i instrumenata za ostvarivanje ciljeva, te shodno ocenjenim šansama, opasnostima i mogućnostima preduzeća, opredeljivanje moguće poslovne strategije.
7. Implementacija strategije tj. nastojanje da se kroz adekvatno kreiranje planova obezbedi harmonično i nesmetano ostvarivanje strategije poslovanja.

8. Kontrola i revizija, realnoo sagledavanje planiranog i ostvarenog.

Iz svega navedenog proizilazi da proces strategijskog menadžmenta treba da usaglasi i odgovori na sledeće izazove:

1. Lokalitet, vizija i svrhs misije preduzeće,

2. Koje performanse i na kom nivou ostvariti ciljeve preduzeća,

3. Kojim putem stići i način izabra strategija preduzeća,

4. Kako implementirati strategiju preduzeća,

5. Na koji način prilagoditi upravljački proces prema postojećim resursima.

\subsection{Opcije rasta preduzeća}

U literaturi postoje brojne i različite klasifikacije strategija rasta. Na osnovu teorije zasnovane na resursima, u predviđanju rasta preduzeća mogu se razlikovati dva pravca. Pravac istraživanja se fokusira na poslovnu strategiju, odnosno procese analize i formulisanja strategije. Preduzeće treba da izabere strategiju koja na najbolji način koristi resurse i sposobnosti u odnosu na eksterne sanse. Postoji empirijska potvrda da resursi preduzeća utiču u određenoj meri na izbor strategije rasta uopšte, a ne samo na diversifikaciju.

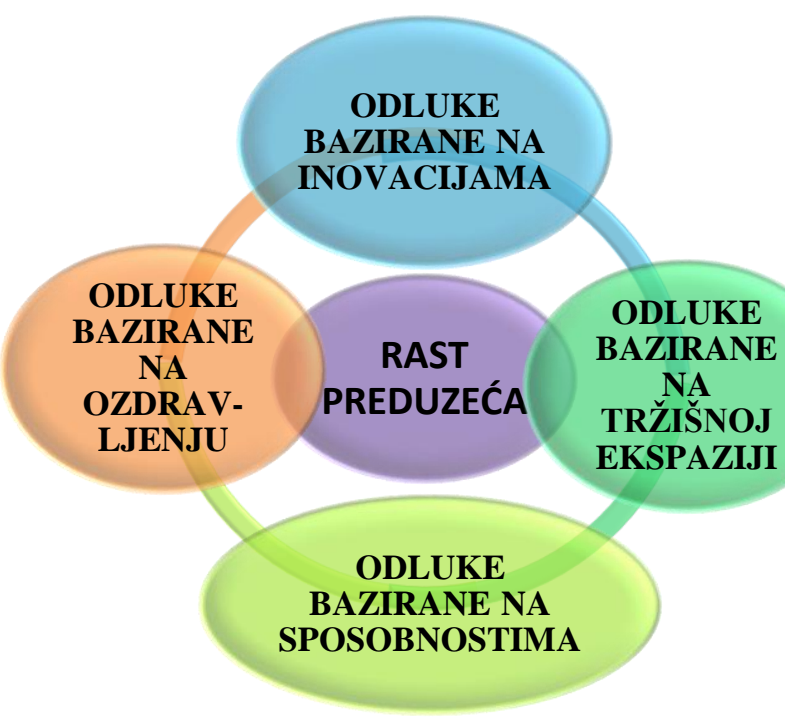

Slika 1. Strategijska opcija rasta preduzeća

Izvor: Autor 
Ansoff razlikuje četiri strategije rasta (slika 1): tržišnu penetraciju, razvoj tržišta, razvoj proizvoda i diversifikaciju (koncentričnu, horizontalnu i konglomeratsku). Rast ostvaren $u$ prethodnom periodu nije pokazatelj budućeg rasta i uspeha preduzeća. (Ansoff, 1984)
U pomenutom istraživanju Canals identifikovao je četiri osnovne opcije rasta: ozdravljenje, inovacije, proširenje sposobnosti (putem alijansi i akvizicija) i tržišna ekspanzija. (Canalis, 2001)

Uspešan rast omogućava simultano korišćenje dimenzija tržišta i sposobnosti preduzeća, a tabela 1 ilustruje načine rasta.

Tabela 1. Sposobnosti i tržišta - dualni pristup rastu preduzeća

\begin{tabular}{|c|c|c|c|}
\hline & \multicolumn{2}{|c|}{ Tržišta/potrošači } \\
\hline & & Postojeći & Novi \\
\hline \multirow{2}{*}{$\begin{array}{l}\text { Resursi i sposobnosti } \\
\text { preduzeća }\end{array}$} & Postojeći & Ozdravljenje & Inovacija \\
\hline & Novi & Proširenje sposobnosti & Tržišna ekspanzija \\
\hline
\end{tabular}

Izvor: Autor

Osnovna poruka navedene klasifikacije je da je neophodno zajedno razmatrati eksterne faktore (privrednu granu, tržišta i potrošače) $i$ interne faktore preduzeća (resurse i sposobnosti). Jedinstveni atributi eksternog i internog konteksta oblikuju četiri navedene opcije. Ozdravljenje je faktor rasta u situaciji kada preduzeće pokušava da korišćenjem postojećih resursa i tržišta ostvari rast. Inovacije su opcija u kojoj preduzeća sa postojećim resursima pokušavaju da privuku nove potrošače. Neka preduzeća pokušavaju da rastu putem merdžera, akvizicija i strategijskih alijansi.

Empirijskim istraživanjem su identifikovane sledeće strategije rasta:" inovacije proizvoda i usluga, interno investiranje, akvizicije, razvoj tržišta, poslovna i organizaciona kontrola i zajednička ulaganja. $\mathrm{Na}$ osnovu istraživanja relevantne literature možemo zaključiti da strategijski pristup tržištu, potrošačima, konkurenciji i drugim navedenim segmentima obuhvata izbor jedne od četiri moguće opcije. (David, 2003, str. 62)

Opcija 1 obuhvata strategijske alternative smanjivanja/rasta zastupljene u literaturi strategijskog marketinga i menadžmenta. Strategije smanjenja ukazuju na redukciju određene strategijske pozicije preduzeća, dok rast označava povećanje, ekspanziju ili ulazak preduzeća na određenu strategijsku poziciju.

Opcija 2 se određuje na osnovu dimenzija proizvod/tržište. Na osnovu ove dve dimenzije mogu se formulisati četiri strategijske opcije: penetracija tržišta, razvoj tržišta, razvoj proizvoda i diversifikacija. Penetracija tržišta se zasniva na postojećim proizvodima i postojećim tržištima. Rast preduzeća se može ostvariti kroz neposrednu ekspanziju (povećavanje budžeta za promociju, povećanje proizvodnje i/ili povećanje obima kupovina) ili putem preuzimanja postojećih konkurenata. Razvoj tržišta obuhvata promociju postojećih proizvoda na nova tržišta i povećanje obima poslovanja, a ostvaruje se na tri osnovna načina:

- afirmacijom novih upotreba proizvoda,

- novim kanalima prodaje i/ili

- geografskom ekspanzijom.

Razvoj proizvoda obično obuhvata ponudu novog ili modifikovanog proizvoda. Međutim, realno je očekivati da će preduzeće u krizi ispoljiti kontraktivno ponašanje $u$ odnosu na navedene četiri pozicije. Suprotno ekspanziji ili tržišnoj penetraciji je strategija žetve ili pokušaj da se "proda" tržišna pozicija putem povećanja kratkoročnih prihoda u zamenu za smanjenje tržišnog učešća. Ovo se postiže redukcijom troškova. Nasuprot razvoju tržišta je tržišna konsolidacija, strategija kojom se smanjuje broj opsluženih tržišnih segmenata. Nasuprot razvoju proizvoda je strategija racionalizacije.

Opcija 3 obuhvata strategijske varijante $u$ koordinatama ekspanzija/smanjenje i stabilnost u odnosu na proizvode/tržišta i funkcije. Interni rast se zasniva na sopstvenim sposobnostima preduzeća, a eksterni se može ostvariti akvizicijama, merdžerima i zajedničkim ulaganjima. Strategije smanjenja mogu imati sledeće dimenzije: poboljšanje performansi smanjivanjem nivoa i/ili obima ciljeva, redukcija troškova i smanjenje obima aktivnosti kroz dezinvestiranje i smanjenje broja funkcija. Na ove strategije se može primeniti interni $i$ eksterni koncept. Interno smanjenje je u suštini "operativni 
zaokret" koji se ogleda u redukciji troškova, povećanju prihoda, smanjivanju sredstava i reorganizaciji proizvoda i/ili tržišta u cilju povećanja efikasnosti. Eksterno smanjenje obuhvata ozbiljnije oblike zaokreta kao što su dezinvestiranje i likvidacija.

Opcija 4 uzima u razmatranje Porterove generičke strategije. Za sticanje i održanje konkurentske prednosti postoje tri opcije: diferencijacija, fokusiranje i liderstvo u troškovima. Diferencijacija obuhvata proizvod ili uslugu sa jedinstvenim karakteristikama u privrednoj grani. Strategija fokusiranja se odnosi na definisanje i dezagregaciju određenog tržišta, grupe potrošača ili tržišnog segmenta. Liderstvo u troškovima se odnosi na postizanje nižih troškova u odnosu na konkurente i zahteva efikasnost, kontrolu i minimalizaciju troškova kao što su troškovi za istraživanje i razvoj, prodaju i promociju. Realizacija pojedinih pravaca rasta uslovljena je, a neophodno je $\mathrm{i}$ da bude usaglašena sa sopstvenim mogućnostima preduzeća kao i sa spremnošću drugih preduzeća i institucija da na različite načine participiraju u određenim projektima. Načini finansiranja rasta preduzeća iz tržišno razvijenih zemalja i zemalja u tranziciji bili su predmet istraživanja koje je obuhvatilo oko 8.000 preduzeća iz 44 države u periodu od 1994. do 2000. godine. Rast je finansiran iz kredita $u$ $49 \%$ preduzeća, interni resursi u $29 \%$, a emisija novih akcija u $22 \%$ ispitivanih preduzeća. (Glen \& Singh, 2003) Korišćenje kredita za finansiranje rasta je znatno manje u zemljama u tranziciji. Nivo razvijenosti finansijskih tržišta determiniše korišćenje nove emisije akcija kao izvora finansiranja rasta preduzeća iz tranzicionih država.

Pod metodom rasta preduzeća podrazumevaju se načini na koji menadžment pribavlja neophodne resurse za realizaciju izabranih pravaca rasta. Metod rasta je način na koji preduzeće realizuje svoje definisane razvojne potrebe i ciljeve. $U$ tom smislu veoma značajnu ulogu imaju odgovarajuće metode rasta, posebno metoda koja je zasnovana na faktoru visine finansijskih sredstava na koje je preduzeće spremno da uloži. Rast preduzeća je uvek uslovljen odgovarajućim materijalnim, odnosno finansijskim ulaganjima.

\subsection{Konkurentnost kao faktor razvoja}

Nijedno preduzeće ne može reći da je u nekom trenutku dovoljno naučila o svojoj industriji, konkurenciji ili načinima na koje može da unapredi svoju konkurentnu poziciju. Strateška pozicija je put, a ne fiksiran položaj. (Popovčić-Avrić, 2006) Od menadžmenta se očekuje strategijski pristup razvoju preduzeća koji će se dominantno zasnivati na integralnoj fleksibilnosti. $U$ uslovima naglašenog integralnog poslovnog ambijenta potreba za fleksibilnošću postoji u svakoj fazi lanca vrednosti.

$\mathrm{Na}$ najširem nivou, moguće je definisati dva osnovna tipa konkurentske prednosti: niska cena, diferencijacija i tri osnovne strategije konkurentnosti (koje mogu biti korišćene ili individualno ili u kombinaciji) za kreiranje strateške pozicije u budućnosti:

- Strategija cenovna (troškovne) prednost,

- Strategija diferencijacije,

- Strategija fokusiranja.

Konkurenti su svi - kupci, dobavljači, potencijalni novi učesnici na tržištu i proizvođači supstituta, a u zavisnosti od grane mogu da budu manje ili više značajni ili aktivni. Konkurentska struktura jedne industrije se može analizirati na osnovu pet konkurentnih sila koje su u literaturi najčešće označene kao Porterove sile. (Vulić, 2009, str. 4) Zajednička snaga tih sila određuje potencijalne mogućnosti jedne delatnosti da ostvari profit. Cilj menadžerskih timova koji kreiraju korporativne strategije je da u industriji steknu položaj u kojem kompanija može najbolje da se brani od opasnosti, a da iskoristi šanse iz okruženja.

Poznavanje osnovnih izvora konkurentskih pritisaka obezbeđuje osnovu za strateški akcioni plan. Ti izvori ukazuju na najvažnije prednosti i nedostatke preduzeća, utiču na pozicioniranje preduzeća u konkretnoj grani i lociraju segmente u kojima strateške promene mogu doneti koristi. Akcioni plan može da uključi:

- pozicioniranje koje preduzeću obezbeđuje najbolju odbranu od konkurentskih snaga;

- uticanje strateškim potezima na ravnotežu sila, čime se popravlja položaj preduzeća; predviđanje značajnih promena faktora na kojima počivaju konkurentske sile i reagovanje na njih. 
Najvažnije za rast, pa čak i za sam opstanak preduzeća je iznalaženje pozicije na tržištu koja je manje izložena opasnosti od napada direktnih protivnika, bilo da se radi o već afirmisanim ili novim preduzećima, odnosno manje ugrožena od strane direktnih kupaca, dobavljača i supstituta. Ovakva pozicija može da se uspostavlja na različite načine među kojima se mogu izdvojiti sledeći: učvršćivanjem odnosa sa najvažnijim klijentima, diferencijacijom proizvoda, uspostavljanjem tehnološkog liderstva u grani ili stupanjem u strategijske poslovne saveze kako bi se iskoristile sinergijske prednosti preduzeća na određenoj tržišnoj poziciji.

Stvaranje održive konkurentske prednosti se uglavnom odvija uz pomeranje industrijskih snaga. $U$ različitim fazama životnog ciklusa industrije preduzeća variraju vrednosne i troškovne pokretače kako bi unapredili svoj tržišni položaj. Ciklus dinamičkog porasta na kome se zasniva jačanje tržišne pozicije počinje investiranjem $u$ inovacije proizvoda ili procesa proizvodnje u cilju povećanja vrednosti, a smanjenja troškova, čime se povećava produktivnost i raste dobit preduzeća. Veća dobit povećava profitabilnost, što obezbeđuje finansijski potencijal za širenje kapaciteta i razvoj preduzeća. $\mathrm{Na}$ osnovu razvoja vremenom se obezbeđuje više izvora za inovacije, što dovodi do uspostavljanja kontinuiranog ciklusa u kome se smenjuju veličina preduzeća, inovativnost, profitabilnost i rast, odnosno razvoj preduzeća

\subsection{Značaj kompetentnosti konkurentnost preduzeća}

Cilj svakog uspešnog menadžmenta je stvaranje i razvijanje kompetencija. Suština kompetentnosti je stalno izražavanje želje i shvatanja, izučavanja procesa, kolektivnog učenja u preduzeću. (Đuričin, Janošević, \& Kaličanin, 2009, str. 67)

Da bi se uspešno ostvarila izabrana korporativna strategija nužno je da menadžment preduzeća utvrdi ili definiše eksplicitni plan akcije koji propisuje način alokacije resursa $i$ drugih aktivnosti u odnosima sa okruženjem i koji pomaže preduzeću da ostvari svoje planirane ciljeve. Na osnovu izabrane strategije razvija se jedinstvena (distinktivna) kompetentnost preduzeća kao nešto što ono posebno dobro radi u odnosu na svoju konkurenciju i na čemu ostvaruje konkurentsku prednost.
Svaka konkurentska prednost povezana je sa kompetentnošću kao setom specifičnih sposobnosti preduzeća koji usmerava upotrebu i razvoj njegovih resursa ka efikasnom ostvarenju postavljenih ciljeva. Manifestuje se kroz serije poslovnih procesa i rutina koje i čini upotreba raspoloživih resursa i pojavne interakcije između njih. Do konkurentske prednosti dovodi samo ona kompetentnost koja omogućava preduzeću da bude bolje od svojih konkurenata i ukoliko se ta superiornost ostvari na tržištu. Ovakav pristup stavlja sve veći naglasak na resurse specifične za konkretno preduzeće i njegov strategijski menadžment i razvijen je kao pristup preduzeću baziran na resursima

Resursno-bazirana teorija preduzeća kao polazište $u$ formulisanju korporativne strategije postavlja analizu internih resursa i sposobnosti preduzeća. Radi se o tome da preduzeća stiču, razvijaju i šire svoje resurse vremenom, pri čemu različiti razvojni putevi preduzeća zahtevaju i različite resurse. Da bi iskoristila svoje specifične resurse preduzeća realizuju različite strategije. Održiva konkurentska prednost ostvaruje se ukoliko preduzeće u procesu implementacije korporativne strategije može da koristi sopstvene resurse i ukoliko konkurenti ne mogu da imitiraju njegovu strategiju. Stoga detaljna analiza resursa preduzeća, njegovih sposobnosti (aktivnosti koje obavlja izuzetno dobro) i kompetencija rezultira boljem razumevanju izvora konkurentske prednosti što predstavlja preduslov za efikasnu realizaciju formulisane korporativne strategije.

Za resursno baziranu korporativnu strategiju eksterno okruženje nije ključni input strategijske akcije preduzeća. Svako preduzeće predstavlja svojevrsnu kolekciju jedinstvenih resursa i sposobnosti koji su osnova za njegovu konkurentnu prednost i korporativnu strategiju. Zbog toga se obavlja analiza koja počinje identifikovanjem izvora resursa i sposobnosti preduzeća i sagledavanjem njegovih slabosti i snaga u odnosu na konkurente (šta je preduzeće u stanju da uradi bolje od konkurenata), zatim treba utvrditi potencijalne resurse i sposobnosti za ostvarenje konkurentske prednosti, odrediti atraktivnu privrednu oblast u kojoj je moguće eksploatisati resurse i sposobnosti preduzeća i formulisati i primeniti odgovarajuću korporativnu strategiju polazeći od tržišnih mogućnosti u eksternom okruženju. Ovako utvrđeni izvori i 
sposobnosti osnova su održive konkurentne prednosti i natprosečnih rezultata preduzeća. (Sekulić, 2006, str. 158)

Jezgro kompetentnosti predstavlja posebnu vrstu, na znanju zasnovanih resursa (povezani set veština, sposobnosti i tehnologija) koji su rezultat kolektivnog učenja i akumuliranog znanja preduzeća o tome kako usklađivati različite proizvodne veštine, kako ih povezivati sa novim tehnologijama i kako na tim osnovama ostvariti odgovarajuću konkurentsku prednost i korporativni uspeh preduzeća. Kriterijumi za identifikovanje jezgra kompetentnosti uključuju obezbeđivanje potencijalnih sredstava za velika tržišta, ostvarivanje značajnog doprinosa od određenog proizvoda ili usluge u pogledu koristi za potrošače i nemogućnost imitiranja od strane konkurenata. (Sekulić, 2006)

Putem razvoja veština ili kompetencija u preduzeću otvaraju se novi putevi njegovih šansi $i$ uspeha na ciljnom tržištu.

Primena koncepta jezgra kompetentnosti transformiše proces upravljanja koji polazi od portfolija poslovnih jedinica i aktivnosti u upravljanje portfoliom kompetentnosti i konkurentnosti putem kompetentnosti. Pojavni oblik jezgra kompetencije je neka funkcionalnost koja jezgro proizvoda i finalni proizvod diferencira $\mathrm{u}$ odnosu na konkurenciju i preduzeću daje konkurentnu prednost. Jezgra proizvoda su komponente koje čine osnovu za veliki broj finalnih proizvoda koji se, najčešće na osnovu sličnosti njihovih tržišta, grupišu u poslovne jedinice i predstavljaju "fizičko otelotvorenje" jednog ili više jezgara kompetentnosti i čine vezu između jezgara kompetentnosti i finalnih proizvoda. Završni, pak, proizvodi su „fizička oličenja" jezgara proizvoda.

Zadatak poslovnog menadžmenta je da odluči šta bi trebalo da bude jezgro kompetentnosti, prvenstveno polazeći od veština i sposobnosti preduzeća ali i dinamičnih tržišnih kretanja. Jednom doneta odluka zahteva potpuno opredeljenje organizacije i odgovarajuće strategijske investicije, što se teško može pravdati samo tradicionalnim kriterijumima stope prinosa na investicije. Zato se i efikasnost formulisanja i primene strategije bazirane na resursima i ključnim kompetentnostima vrednuje adekvatnom kombinacijom postojećih kriterijuma efikasnosti, pri čemu se, zbog složenih relacija između kriterijuma, pri izboru merila vrši odgovarajuća „kriterijumska“ analiza, kako bi se na pravi način ocenila efikasnost.

\section{ZAKLJUČAK}

Od poslovnog menadžmenta se očekuje da, raspolažući sa relevantnim signalima koji nose poruke iz okruženja, uvek uspostavlja takav odnos sa sredinom koji će mu omogućiti da ima prave ciljeve, da deluje u skladu sa mogućnostima i bude uvek u pripravnosti da deluje prema novim okolnostima i zahtevima okruženja.

Ostvarivanje ciljeva i pravaca rasta preduzeća obuhvata značajne investicije u proširenje postojećih kapaciteta, ali i u izgradnju novih. Rast preduzeća podrazumeva jačanje osnovne delatnosti i/ili ulazak u nova područja poslovanja i samim tim i oštriju konkurenciju.

Kreiranje održive konkurentske prednosti pretpostavlja sinergijsko delovanje vrednosnih $\mathrm{i}$ troškovnih pokretača, kao i izvora i sposobnosti koje stvaraju pokretači. $U$ isto vreme od menadžmenta preduzeća se očekuje da kreira takvu strategiju koja će sprečiti ili znatno umanjiti imitacije proizvoda ili proizvodnih procesa od strane konkurenata, kao i da obrazuje kupce kako se ne bi orijentisali ka supstitutima koje proizvode konkurenti.

Jezgro kompetentnosti je vrlo značajna alatka za analitičko ispitivanje $\mathrm{i}$ iskorišćavanje internih snaga preduzeća. Identifikujući svoje jezgro kompetentnosti preduzeće može da pređe na ispitivanje mogućih šansi u kojima njegove ključne sposobnosti mogu da dovedu do novih proizvoda ili novih tržišta. Zahvaljujući jezgru kompetentnosti preduzeća ostvaruju veću sinergiju između poslovnih jedinica kroz pronalaženje njihovih zajedničkih interesa, problema, sposobnosti ili šansi za efikasnije poslovanje. Smatra se da svako preduzeće koje uspešno plasira na tržištu sa odgovarajućom stopom dobiti ostvaruje konkurentnu prednost, u odnosu na konkurente.

Svaka konkurentska prednost povezana je sa kompetentnošću kao setom specifičnih sposobnosti preduzeća koji usmerava upotrebu i razvoj njegovih resursa ka efikasnom ostvarenju postavljenih ciljeva. Manifestuje se kroz serije poslovnih procesa i rutina koje i čini upotreba raspoloživih resursa i pojavne interakcije između 
njih. Do konkurentske prednosti dovodi samo ona kompetentnost koja omogućava preduzeću da bude bolje od svojih konkurenata i ukoliko se ta superiornost ostvari na tržištu.
Rast preduzeća je uvek uslovljen odgovarajućim materijalnim, odnosno finansijskim ulaganjima.

\section{CITIRANA DELA}

Ansoff, I. (1984). Implanting Strategic Management. Prentice Hall.

Canalis, J. (2001). How to Think About Corporate Growth? EuropeanManagemenr Journal, 19(6), 487589.

David, F. (2003). Strategic Management: Concepts and Cases (9 izd.). New Jersey: Prentice Hall.

Đogić, R. (2007). Osnovi savremenog menadžmenta. Sarajevo: Štamparija Fojnica-d.o.o. Fojnica.

Đuričin, D., \& Janošević, S. (2006). Menadžment i strategija. Beograd: Ekonomski fakultet.

Đuričin, N., Janošević, V., \& Kaličanin, Đ. (2009). Menadžment istrategija. Beograd: Centar za izdavačku delatnost, Ekonomski fakultet.

Glen, J., \& Singh, A. (2003). Capital Structure, Rates of Return and Financing Corporate Growth: Comparing Developed and Emerging Markets, 1994-00. Cambridge. : Working Papers wp265, Centre for Business Research, University of Cambridge.

Popovčić-Avrić, S. (2006). Konkurentnost- ključni faktor strategije razvoja preduzeća. Beograd: Fakultet za ekonomiju, finansije i administraciju.

Porter, M. (2009). Konkurentska prednost. Zagreb: Masmedia.

Sekulić, V. (2006). Konkurentna prednost i koorporativni uspeh preduzeća. Ekonomske teme, XLIV(4$5)$.

Vulić, V. (2009). SWOT analiza. Podgorica: Ekonomski fakultet Podgorica.

Datum prve prijave:

Datum prijema korigovanog rada

Datum prihvatanja članka:
05.03.2020.

05.04.2020.

07.04.2020.

Kako citirati ovaj rad? / How to cite this article?

Style - APA Sixth Edition:

Stojanović, V., \& Ivanković, S. (2020, 04 15). Menadžment u funkciji rasta i razvoja preduzeća. (Z. Čekerevac, Ur.) FBIM Transactions, 8(1), 160-167. doi:10.12709/fbim.08.08.01.17

Style - Chicago Sixteenth Edition:

Stojanović, Vladimir, i Svetlana Ivanković. 2020. „Menadžment u funkciji rasta i razvoja preduzeća.“ Urednik Zoran Čekerevac. FBIM Transactions (MESTE) 8 (1): 160-167. doi:10.12709/fbim.08.08.01.17.

Style - GOST Name Sort:

Stojanović Vladimir i Ivanković Svetlana Menadžment u funkciji rasta i razvoja preduzeća [Časopis] // FBIM Transactions / ur. Čekerevac Zoran. - Beograd : MESTE, 1504 2020. - 1 : T. 8. - str. 160-167.

Style - Harvard Anglia:

Stojanović, V. \& Ivanković, S., 2020. Menadžment u funkciji rasta i razvoja preduzeća. FBIM Transactions, 15 04, 8(1), pp. 160-167.

Style - ISO 690 Numerical Reference:

Menadžment u funkciji rasta i razvoja preduzeća. Stojanović, Vladimir i Ivanković, Svetlana. [ur.] Zoran Čekerevac. 1, Beograd : MESTE, 1504 2020, FBIM Transactions, T. 8, str. 160-167 